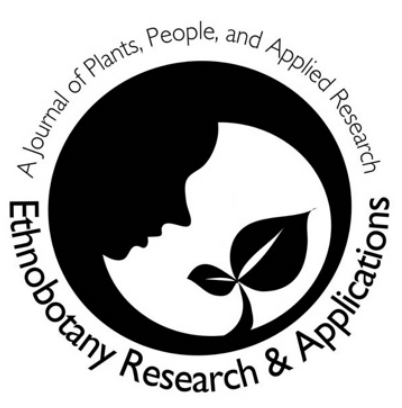

\title{
Cuentos en Etnobiología como Estrategia de Valorización y Rescate de la Memoria Biocultural
}

\author{
Short Stories in Ethnobiology as a \\ Strategy for Valorization and Rescue of \\ Biocultural Memory
}

\author{
Jorge Izaquiel Alves de Siqueira
}

\section{Poesía y cuentos}

\section{Resumen}

El cuento es un género textual de gran flexibilidad, acercándose a la poesía y la crónica, el cual es reconocido por su estructura corta y cerrada. En comunidades campesinas de todo el planeta los cuentos orales funcionan como método de transmisión y aprendizaje cultural, actuando como importantes elementos que aseguran el mantenimiento de la bioculturalidad, una vez que mezclan las situaciones de experiencias empíricas y creencias, es decir, las experiencias que se producen en las interrelaciones entre el hombre y el medio natural, $y$, por lo tanto, determinan comportamientos, los cuales son conocidos como comportamientos bioculturales. En este trabajo se presenta un cuento como estrategia escrita de valorización y rescate de la memoria biocultural local. El cuento es resultado de experiencias etnobotánicas a lo largo de cuatro años, tanto en Brasil, como en Colombia. En el texto se puede identificar rasgos y/o comportamientos bioculturales, sentimientos, descripciones de lugares y otros elementos que nos llevan a imaginar la escena y/o vivirla en nuestra imaginación. Así, el cuento como un relato escrito es una excelente estrategia de valorización y rescate de la memoria biocultural, capaz de despertar el interés en todos los rangos de edad, especialmente, entre los más jóvenes, transcendiendo generaciones. Además, el cuento se estructura como una reflexión al quehacer de los etnobiólogos en la afirmación de que debemos trabajar de la comunidad para la comunidad.

\footnotetext{
Abstract

The short story is a textual genre of great flexibility, approaching poetry and chronicle, which is
}

recognized by its short and closed structure. In rural communities around the world, oral tales' function as a method of cultural transmission and learning, acting as important elements that ensure the maintenance of bioculturality, once they combine the situations of empirical experiences, and beliefs, that is, the experiences produced in the interrelationships between human and the natural environment, and therefore, determining behaviors, which are known as biocultural behaviors. In this paper, I present a short story as a written strategy of valorization and rescue of local biocultural memory. The short story is the result of ethnobotanical experiences over four years, both in Brazil, and in Colombia. In the text, features and/or biocultural behaviors, feelings, descriptions of places and other elements that lead us to imagine the scene and/or live it in our imagination can be identified. Thus, the short story as a written story is an excellent strategy of valorization and rescue of biocultural memory, capable of awakening interest in all age ranges, especially among the youngest, transcending generations. In addition, the short story is structured as a reflection on the work of ethnobiologists in the affirmation that we must work from the community to the community.

\begin{tabular}{l} 
Correspondence \\
Jorge Izaquiel Alves de Siqueira \\
Pregrado en Biología \\
Universidad Federal de Piauí (UFPI) \\
Campus Ministro Reis Velloso (CMRV), 64202-020, \\
Parnaiba, Piauí, \\
Brasil. \\
ethnosiqueira@gmail.com \\
Ethnobotany Research \& Applications \\
$\mathbf{1 7 : 4 ~ ( 2 0 1 8 )}$ \\
\hline
\end{tabular}




\section{Resumo}

O conto é um gênero textual de grande flexibilidade, aproximando-se da poesia e da crônica, o qual é reconhecido por sua estrutura curta e fechada. Em comunidades camponesas de todo o planeta os contos orais funcionam como método de transmissão e aprendizagem cultural, atuando como importantes elementos que asseguram a manutenção da bioculturalidade, uma vez que mesclam as situações empíricas e crenças, é dizer, as experiências que se produzem nas inter-relações entre o homem e o meio natural e, portanto, determinam comportamentos, os quais são conhecidos como comportamentos bioculturais. Neste trabalho, se apresenta um conto como estratégia escrita de valorização e resgate da memória biocultural local. O conto é resultado de experiências etnobotânicas ao longo de quatro anos, tanto no Brasil, como na Colômbia. No texto se pode identificar traços e/ou comportamentos bioculturais, sentimentos, descrições de lugares e outros elementos que nos põem a imaginar a cena e/ou vivê-la em nossa imaginação. Assim, o conto como um relato escrito é uma excelente estratégia de valorização e resgate da memória biocultural, capaz de despertar o interesse em todas as faixas etárias, especialmente, entre os mais jovens, transcendendo gerações. Ademais, o conto se estrutura como uma reflexão ao labor dos etnobiólogos na afirmação de que devemos trabalhar da comunidade para a comunidade.

\section{Del bosque hacemos nuestra felicidad y bioculturalidad}

Las investigaciones de carácter etnobiológico son caracterizadas por diferentes contextos. Por ello, en estos ambientes se registran que las herencias ecológicas y culturales varían de región a región. Así, los investigadores aprenden a lidiar con nuevas culturas, se ajustan a los patrones del área en estudio, aceptan las reglas locales y vivencian situaciones únicas que jamás podrían ser consecuencia del conocimiento científico. Ya se transcurrió un par de meses desde que se me ocurrió la experiencia que les contaré, pero en realidad se mantiene activa en mi memoria y/o recuerdos. La verdad es que no sé si me hago una laguna de lágrimas por recordarlo o si me quedo repleto de felicidad por darme cuenta de que la simplicidad puede ser sinónimo de buen-vivir.

Era jueves, el sol brillaba intensamente y tuve que levantarse temprano para irme al campo a recoger datos etnobotánicos sobre huertos familiares. Los pájaros cantaban, la gente trabajaba, eran niños, señoras, adultos, todos iban a buscar leña en el bosque, a recolectar frutos y a cazar para garantizar su propia subsistencia. Ya había finalizado casi todas las encuestas, pero me faltaba una de ellas. Al mirar en el mapa, me di cuenta, de lo alto la casa se veía chiquita, aún no había sido blanco de entrevista. Era un poco lejana, yo ni siquiera sabía de su existencia. Al caminar por la vereda, un hombre interrumpe mi caminata. Suspiró fuerte, me miró levemente y no dudó en preguntarme:
- ¡Hola, señor! Está perdido, ¿verdad?

- ¡Hola! Estoy buscando una casa, necesito ir allá cuanto antes. Es una casa un poco lejos de acá.

- Y esa casa que busca, ¿sabe usted la ubicación de ella?

- Sí, de verdad sé más o menos, señor. Se ubica por aquellos lados (Apunté a un lado en dónde se ubicaba más o menos la vivienda que buscaba).

- ¡Ah, ya, señor! Entonces ya sé su ubicación y sé que es lejos, pero no se preocupe. Usted sólo debe seguir por esta vereda y en poco tiempo llegará a la vivienda que busca.

- ¿En serio? Muchas gracias, no sé como agradecerle a usted. Que tenga un buen día (Quedé muy contento por su información).

- Muchas gracias, a usted igualmente, señor.

Quedé muy contento por las indicaciones dadas por el señor, entonces, seguí caminando por la vereda que me había mencionado, caminé más o menos una hora y media hasta que llegué a la vivienda. Al encontrarla, de lejos, vi a una pareja de ancianos, estaban cerca de una laguna que recorría entre los cercos de madera que rodeaban su casa. Era una vivienda muy humilde, hecha de barro y madera, techo de hojas de una palmera, pero era muy hermosa e increíble. El huerto era diverso, una inmensa diversidad de especies, árboles de mango, plátanos, muchas hierbas, etcétera. La diversidad era tan grande que mis ojos brillaban. Era todo muy hermoso, me hipnoticé por lo que acababa de ver. Sentí unos pellizcos en mi brazo.

- ¡Ay! (Grité duro).

- Tranquilo, señor. Discúlpeme, sólo te he visto ahí parado, ¿estás bien? (Me habló la señora).

- No pasa nada, perdónenme por el susto (Nos reímos juntos).

- ¿Quieres entrar a la casa? Mire... es por acá que se entra.

- Me encantaría, ¡muchas gracias, señora!

Entré a través de una chiquita puerta que había en medio de la cerca, la señora me guio hasta su vivienda, le mencioné la propuesta de la investigación, y tras esto, ella ha manifestado interés en participar del estudio. Hemos resuelto darnos un tiempo para platicar, el día se estaba volviendo nublado. Percibiendo este cambio en el cielo, la señora se dirigió en palabras para mí:

- ¿No te gustaría entrar y quedarte un rato? Va a llover y no podrás irte.

- ¡Muchas gracias, con su permiso! (Le dije a la señora).

- Siéntate allí en aquella silla, no te preocupes, no caerás al piso. Es hecha de madera del bosque, es muy resistente, te lo aseguro.

Me senté en la silla, era una silla muy confortable, artesanal. A partir de entonces, jugamos conversaciones al viento, jugamos historias al tiempo y al momento. 
- Señora, ¿cómo es vivir aquí? (Le pregunté en tono de curiosidad).

- Oye... mi hijito. Vivir acá es perfecto, aquí tenemos de todo, hay frutos, hay plantas para hacernos nuestros remedios, la gente de acá también caza mucho en el bosque, nosotros tenemos de todo para ser felices (Me respondió con la mayor felicidad, llenándose de contagiosas sonrisas).

Después de largas conversaciones, sin darnos cuenta, la torrencial lluvia suavizó nuestra plática. La casa era increíble, a pesar de que tanta agua caía, ni una gota siquiera llegaba a mi piel, el techo estaba hecho con hojas de una palmera. Se notaba que había sido construido con mucha dedicación y amor. En medio de la lluvia, llega su esposo todo mojado, se llamaba Manuel, entró en la casa y se dirigió a su esposa:

- ¡Mujer, ayúdame aquí, por favor! Mire lo que capturé para ti (Le habló como si estuviera con mucho frío).

- ¿Pero qué es esto hombre? Dígame de una vez, no me mate de corazón, hombre.

El señor Manuel le saca una serpiente desde una trampa hecha de madera. Era un reptil muy grande. El señor se veía muy contento, suspiró intensamente y se notaba que el frío le afectaba la voz, pese a esto consiguió hablarle a su esposa:

- Oye Joaquina, ahora podrás tratar los dolores en tus piernas, ahora ya no te irás a quejar cuando nosotros vayamos a dormir.

- Oh Manuel, estoy sin palabras, la verdad es que no sé que decirte. Estoy muy contenta. Ya hace un largo periodo que he intentado capturar una serpiente de éstas, pero nunca lo he logrado y tú lo consigues justo hoy (La felicidad se notaba perfectamente en el rostro de la señora Joaquina).

Después de todo ese susto, volvemos a platicar, en medio de la conversación, ella percibió que yo me había distraído, el estilo de la casa me ha dejado con la boca abierta, me ha fascinado por completo. Las paredes, los muebles, todo muy natural y rústico y a la vez tan hermoso, e incluso, una higiene impecable. Me porté como si estuviera tímido... dándose cuenta, doña Joaquina se ha volteado hacía mí a indagarme:

- ¿Qué te pasa? Puedes mirarle a todo, no te avergüences. La casa es pobre, pero nosotros somos felices viviendo acá. Puedes mirar todo mi hijito, no te preocupes, ¿vale?

- Muchas gracias, señora. Acá todo es muy increíble. Las ollas son de barro, las paredes son fantásticas. ¿Fueron ustedes los que construyeron esta casa? (Le pregunté muy encantado con la vivienda).

- Sí, fuimos nosotros. Mi esposo y yo lo hicimos todo. Nosotros recolectamos todos los materiales en el bosque. El barro fue de allí cerca de los alrededores de casa, los muebles son casi todos hechos de madera del bosque. Mi esposo Manuel sabe hacer muchas cositas así. Nosotros fuimos poco a poco construyendo nuestra casita, nuestro patio, nuestras plantitas. Todo que hay aquí proviene del bosque, allí encontramos de todo que necesitamos para ser felices.

En medio a nuestra plática, algo sobre un tronco de madera me roba la atención. Era un animal atrapado en una botella de vidrio. El animal se movía sin pararse, yo seguía con los ojos sus movimientos, pero no sabía que bicho era. El ambiente estaba un poco oscuro y, así, no pude darme cuenta de que se trataba. Doña Joaquina se enteró de mi distracción.

- ¿Qué estás mirando? Tienes miedo, ¿cierto? Es sólo una tarántula. La he atrapado hoy (La señora no paraba de bostezar, se moría de sueño).

- ¿Es una tarántula? ¡Que enorme se ve! ¿Y con qué propósito usted la atrapó? (En este momento mis piernas temblaban, pero no de miedo, sino de afán por escucharla).

- Mira mijito, la capturé para hacerme un remedio mañana, yo hago una mezcla con un montón de árboles del bosque, sirve para un par de problemas del cuerpo. Lo aprendí todo esto con mis papás y abuelitos. Es este conjunto conocimientos que me salvan en situaciones de emergencia. ¡Si no fuera esta tarántula, yo estaría muerta! Nosotros las mujeres tenemos un montón de problemas de salud, ¿si me hago entender?

- ¿Y los pelos de la tarántula? (Le pregunté muy sorprendido).

Al cuestionarla percibí que ya no se encontraba despierta, estaba casi dormida allí mismo en la silla. Aquel hecho me robara la atención. Era increíble lo que esta señora me había relatado. Yo tenía ansiedad por conocer más sobre las prácticas asociadas a los usos medicinales de la araña. Ya era tarde, la lluvia no se detenía. Fui invitado por el señor Manuel para dormir allí mismo. Le agradecí la invitación y me acosté en el piso. El señor Manuel se acercó a mí y cubrió mi cuerpo con un par de hojas.

- Voy a cubrirte con estas hojas, no te preocupes, lo hago para que ningún insecto y/o zancudo se te pique a lo largo de la noche (Me dijo en voz bajita para no despertar a su esposa).

- ¡Muchas gracias, señor Manuel!

Intenté dormir, pero no lo logré. Me quedé imaginando un montón de cosas. Cuando me llegó el sueño, adormecí sin darme cuenta. Al despertar, miré al reloj, hice un vistazo a todos los lados de la casa y no vi a nadie. Ya eran nueve horas de la mañana. Yo estaba retrasado de tiempo. La pareja ya no se encontraba en su vivienda, habían salido al bosque, tal vez salieron muy temprano, quizá en la madrugada. Regresé a la casa de ellos a lo largo de varios días, pero nunca volví a encontrarlos otra vez. Nadie nunca supo decirme lo que ha pasado con la pareja de ancianos. Que se trasladaron a otro sitio, tal vez. 